\title{
Unidirectional photodamage of pheophytin in photosynthesis
}

\author{
Harvey J. M. Hou* \\ Department of Physical Sciences, Alabama State University, Montgomery, AL, USA \\ ${ }^{*}$ Correspondence: hhou@alasu.edu
}

Edited by:

Suleyman I. Allakhverdiev, Russian Academy of Sciences, Russia

Reviewed by:

Mohammad M. Najafpour, Institute for Advanced Studies in Basic Sciences, Iran

\section{Keywords: pheophytin, photosystem II, electron transfer, photodamage, photoinhibition}

The primary reactions in photosynthesis take place in the reaction centers surrounded by light harvesting complexes (Blankenship, 2002; Diner and Rappaport, 2002; Frank and Brudvig, 2004). There are two types of photosynthetic reaction centers. The type I reaction center has ironsulfur cluster as stable electron acceptor, such as photosystem I complexes, green bacterial and heliobacterial reaction centers, and the type II uses quinone as stable electron acceptor including photosystem II and purple bacterial reaction centers. The electron transfer in type II reaction center in unidirectional via the L-subunit of the reaction centers (Maroti et al., 1985; Hoerber et al., 1986; Martin et al., 1986; Michel-Beyerle et al., 1988). However, the electron transfer in the type I reaction center is different from that in the type II centers, which is bidirectionational (Guergova-Kuras et al., 2001; Li et al., 2006). The three dimensional structures of both types of reaction centers were determined at atomic resolution (Jordan et al., 2001; Ferreira et al., 2004; Loll et al., 2005; Amunts et al., 2007; Umena et al., 2011). The electron transfer pathways in both types of reaction centers are well established (Van Grondelle, 1985; Schatz et al., 1988; Fleming and van Grondelle, 1997; Dekker and Van Grondelle, 2000; Gobets and van Grondelle, 2001; Seibert and Wasielewski, 2003; Van Grondelle and Novoderezhkin, 2006). The primary electron donor in the reaction centers is a pair of chlorophyll molecules, and pheophytin is the primary electron acceptor (Klimov et al., 1977; Holzwarth et al., 2006).

Light is the only source of energy for photosynthesis; it can also be harmful to plants (Powles, 1984). During the recent 10 years the molecular processes of photoinhibition had been intensively studied (Adams and Demmig-Adams, 1993; Aro et al., 1993; Baker and Bowyer, 1994; Anderson et al., 1997; Asada, 1999; Melis, 1999; Niyogi, 1999; Adir et al., 2003; Telfer, 2005; Murata et al., 2007; Tyystjarvi, 2008; Kramer, 2010; Hou and Hou, 2013). The PSII complex is composed of more than 15 polypeptides and 200 pigment molecules. Because there are many pigment and protein molecules not related directly to the photoinhibition reaction, it is difficult to identify which molecule is photodamaged. The preparation of PS II reaction center D1/D2/cytochrome b-559 complex, which contains only a few polypeptides and pigments, can be a good material to meet the difficulty (Nanba and Satoh, 1989).

The PS II reaction center D1/D2/cytochrome b-559 complexes from higher plants contain five polypeptide subunits (Seibert et al., 2004). It contains six chlorophyll a ( $\mathrm{Chl}$ a), two $\beta$-carotene (Telfer et al., 1987; Seibert et al., 1988; Gounaris et al., 1990; Kobayashi et al., 1990; Barbato et al., 1991). The PSII reaction center does not contain the quinone electron acceptors $\mathrm{Q}_{\mathrm{A}}$ and $\mathrm{Q}_{\mathrm{B}}$. It photochemical reaction is restricted to radical pair formation and recombination (Takahashi et al., 1987; Crystall et al., 1989; Wasielewski et al., 1989). Addition of exogenous electron donors and acceptors allows secondary electron flow reaction to occur. Therefore the D1/D2/cytochrome b-559 complex constitutes a good simple system for probing on the mechanisms from both acceptor-side and donor-side photoinhibition (Barber and Andersson, 1992; Barber and De Las Rivas, 1993; Yu et al., 1995). It has found that primary electron donor $\mathrm{P}_{680}$, accessary chlorophyll, carotene, amino acid residues such as histidine, and pheophytin are vulnerable to excess light.

The primary electron donor $\mathrm{P}_{680}$ of PSII can be damaged easily by exposure of strong light, when no additions are made (Telfer and Barber, 1989). Singlet oxygen is formed as a consequence of radical pair recombination (McTavish et al., 1989; Durrant et al., 1990). The generation of this highly toxic species causes initially a selective and irreversible bleaching of the chlorophylls that constitute $\mathrm{P}_{680}$ and a breakdown of the D1 protein to a $23-\mathrm{kDa}$ fragment containing the $\mathrm{N}$ terminus of the complete protein (De Las Rivas et al., 1993). In the presence of a suitable electron acceptor such as silicomolybdate or decylplastoquinone, the $\mathrm{P}_{680}+$ lifetime is increased, and irreversible bleaching of $\beta$-carotene and chlorophyll are observed, which are independent of oxygen (Telfer et al., 1991). Under these conditions breakdown of the $\mathrm{D} 1$ protein leads to a $24-\mathrm{kDa}$ fragment of C-terminal origin (Shipton and Barber, 1991).

The photobleaching at $680 \mathrm{~nm}$ is usually attributed to the photodamage of $\mathrm{P}_{680}$ in the PS II reaction center (Telfer et al., 1990). There is the significant overlapping of absorption of $\mathrm{P}_{680}$, accessary chlorophyll, and pheophytin in the PS II reaction center (Diner and Rappaport, 2002). Using high performance liquid chromatography (HPLC) the one pheophytin in PS II reaction center is photo damaged (Hou et al., 1995; Kuang et al., 1995). The time course of pheophytin photodamage showed the content of pheophytin decreases faster than that of chlorophyll, suggesting that 
light-induced damage of pheophytin and $\mathrm{P}_{680}$ occurred step by step in which pheophytin photodamage first and followed by $\mathrm{P}_{680}$ (Hou et al., 1996). The kinetics of the photodamage reaction of $\mathrm{P}_{680}$ suggested that the photodegradation product of $\mathrm{P}_{680}$ photodamage is possibly a pheophytin-like molecule (Peng et al., 1999).

A photoprotective hypothesis of pheophytin against photoinactivation induced from acceptor-side in PS II was proposed (Hou et al., 1996). When $\mathrm{P}_{680}$ bounding to D1 and D2 proteins is excited by light energy, primary charge separation takes place and the radial pair $\mathrm{P}_{680}{ }^{+}$ $\mathrm{Pheo}^{-}$is formed, in which the excited state $\mathrm{P}_{680}$ ejects and transfers one electron to the primary electron acceptor pheophytin bound to D1 protein. Since primary quinone electron acceptor $\mathrm{Q}_{\mathrm{A}}$ is lost in the preparation of PS II reaction center complex, the radical pair may be recombined and the $\mathrm{P}_{680}$ triplet is formed. The singlet oxygen generated by the reaction of the triplet $\mathrm{P}_{680}$ and oxygen in the solution is a highly toxic species to PS II reaction center. The pheophytin molecule probably bound to D2 protein firstly damaged by the singlet state oxygen. More excitation energy accumulated in PS II may cause the photodestruction of $\mathrm{P}_{680}$ and accessary chlorophyll. The photodamage of $\mathrm{P}_{680}$ and accessory chlorophyll resulted in the loss of photochemical activity of PS II. The role of the pheophytin molecule bound to D2 subunit is probably to remove the singlet state oxygen as a result protecting $\mathrm{P}_{680}$ against the photoinduced damage. A study of photoinhibition in vitro and in vivo concluded that photoinhibition in intact pea leaves at low temperature is mainly due to the acceptor-side mechanism (Shipton and Barber, 1994). The unidirectional photodamage and photoprotection of pheophytin is probably the important scheme by which the photoinhibitory reaction takes place in green plants in vivo.

As we discussed early, the role of the second or inactive electron transfer branch is unclear. Because the pheophytin molecule on D2 protein is the key component of the second electron-transfer branch in the PS II reaction center, the unidirectional photodamage of pheophytin infer that the role of the second branch is to protect the first one. In other words, the function of the second electron-transfer branch is to remove the singlet state oxygen species using the pheophytin molecule on $\mathrm{D} 2$ protein.

As PS II and purple bacterial reaction centers are both belong to the type-II reaction centers, the significant similarity in both structure and function are expected. During the early stages of the photoinhibition of isolated spinach PS II reaction center there is a loss of pheophytin (Hou et al., 1995; Kuang et al., 1995). To see if the process of photoinhibition is similar or different between the purple bacterial and plant reaction centers, the photosynthetic pigments and their correlation to the photochemical activity of the isolated reaction centers from $R b$. sphaeroides were assessed (Hou et al., 2005). The experimental data demonstrated: (1) One bacteriopheophytin molecule associated with photochemical activity of the isolated reaction center from $R b$. sphaeroides is damaged under strong light illumination; (2) The damaged bacteriopheophytin is likely located in the $\mathrm{L}$ subunit of the reaction center; (3) The special pair $\mathrm{P}_{870}$ undergoes a two-step photodamage reaction.

Further investigation on the photodamage mechanisms of bacteriopheophytin in the reaction centers from $R b$. sphaeroides is conducted by using liquid chromatography-mass spectrometry (Hou, 2008). The experimental results show that one of the two bacteriopheophytin molecules in the purple bacterial centers accompanying with the complete loss of photoactivity is damaged under strong illumination due to the destruction of its chemical structure. Three degradation products of the bacteriopheophytin photodamage reactions are identified and probably produced by the hydration, dehydrogen, and de-methylation of bacteriopheophytin molecule under strong light conditions. The main degradation product is probably formed by the demethylation at C-8 in the bacteriopheophytin molecule.

Which pheophytin in PS II is more sensitive to strong light is currently unknown and need further investigation. The pigment analysis using HPLC and UV-vis-NIR spectroscopy indicates that one pheophytin in PS II and purple bacterial reaction center is more photosensitive than the other (Hou et al., 1996, 2005). The damaged pheophytin may be bound to D1 or D2 proteins (Figure 1). The HPLC and photochemical activity analysis suggested that the damaged pheophytin is likely in the inactive branch in PS II reaction center complex. However, we cannot exclude that possibility of the alternative option,

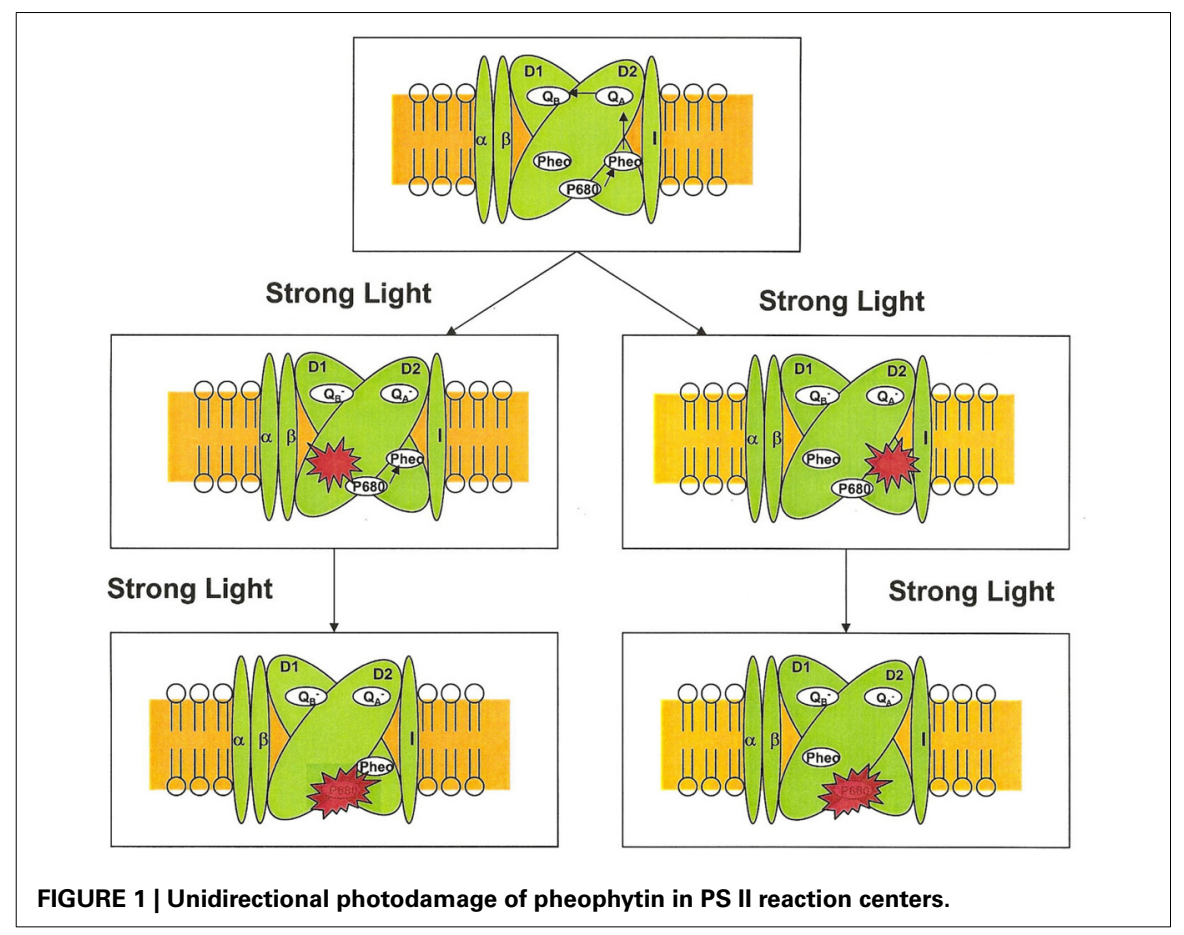


i.e., the damaged pheophytin is located in the active is via D1 protein. This notion is supported by the observation that the photodamage of bacteriopheophytin in purple bacterial reaction center seems to be located in L-subunit.

The pheophytin mutants of Synechocystis sp. PCC 6803 might be useful to provide additional evidence on the site of the photosensitive pheophytin in photosynthesis. Two mutants, D1-Leu210His and D2-Leu209His, wherein the pheophytin in D1 and D2 protein is replaced by a chlorophyll, respectively. In these two mutants, there is only one pheophytin per reaction center. In the D1-Leu210His mutant, the only pheophytin in the reaction center is bound to D2 protein. If the photo damaged pheophytin in D2 protein, the photodamage of pheophytin would be expected in the D1-Leu210His mutant. Alternatively, if the pheophytin in D1 protein is more photosensitive, one would observe that photodamage of pheophytin in the D2-Leu209His mutant.

Unidirectionality of pheophytin photodamage might involve electron transfer reaction. For example, upon excitation with blue light $(390 \mathrm{~nm})$ a transient B-side charge separated electron transfer was observed in picoseconds at room temperature (Haffa et al., 2003). A series of mutations involving the introduction of potentially negative amino acids in the vicinity of $\mathrm{P}_{870}$ were characterized in terms of the nature of this reaction. Bside electron transfer in bacterial reaction center from $R b$. sphaeroides was proposed to be possible photoprotection via rapidly quenching higher excited states of the reaction center (Lin et al., 2001).

Unidirectional electron transfer and photodamage are also discovered in other cofactors such as carotenoid in PS II. The reaction centers of PS II contain two types of $\beta$-carotene with different orientations. The $\beta$-carotene (I) absorbing at 470 and $505 \mathrm{~nm}$ is roughly parallel to the membrane plane, and $\beta$-carotene (II) absorbing at 460 and $490 \mathrm{~nm}$ seems to be perpendicular orientation (Breton and Kato, 1987) The linear dichroism signal at $485 \mathrm{~nm}$ in the PS II core complex CP47/D1/D2/cytochrome b-559 is decreased upon strong illumination (Hou et al., 2000). The observation may be explained as the conformation changes of $\beta$-carotene (II) pool, which tends to more perpendicular orientation respective to the membrane plane.

Multiple photoprotective hypotheses have been established including Mn-mediated UV photoinactivation (Hakala et al., 2005; Ohnishi et al., 2005; Wei et al., 2011; Hou et al., 2013), cytochrome b-559 cyclic electron flow or cytochrome b-559 reversible interconvertion between the two redox forms (Thompson and Brudvig, 1988; Barber and De Las Rivas, 1993; Shinopoulos and Brudvig, 2012), and a $\beta$-carotene photooxidation (Telfer et al., 2003; Alric, 2005; Shinopoulos et al., 2014). The unidirectional photodamage of pheophytin in photosynthesis is discovered. However the site of the damage pheophytin is unknown. The possible function of the pheophytin in photosynthesis is complex and likely involves forward electron transfer, photoprotection, structural support, photosynthetic evolution, and alternative electron transfer. Further investigation using biophysical techniques and mutagenic methods is required to approve or exclude these possibilities.

\section{ACKNOWLEDGMENTS}

This work is supported by Alabama State University.

\section{REFERENCES}

Adams, W. W. 3rd., and Demmig-Adams, B. (1993). Energy dissipation and photoprotection in leaves of higher plants. Curr. Top. Plant Physiol. 8, 27-36.

Adir, N., Zer, H., Shochat, S., and Ohad, I. (2003). Photoinhibition - a historical perspective. Photosyn. Res. 76, 343-370. doi: 10.1023/A:1024969518145

Alric, J. (2005). In vivo carotenoid triplet formation in response to excess light: a supramolecular photoprotection mechanism revisited. Photosyn. Res. 83, 335-341. doi: 10.1007/s11120-005-1105-3

Amunts, A., Drory, O., and Nelson, N. (2007). The structure of a plant photosystem I supercomplex at 3.4.ANG. resolution. Nature 447, 58-63. doi: 10.1038/nature05687

Anderson, J. M., Park, Y. L., and Chow, W. S. (1997). Photoinactivation and photoprotection of photosystem II in nature. Physiol. Plant. 100, 214-223. doi: 10.1111/j.1399-3054.1997.tb04777.x

Aro, E. M., McCaffery, S., and Anderson, J. M. (1993). Photoinhibition and D1 protein degradation in peas acclimated to different growth irradiances. Plant Physiol. 103, 835-843.

Asada, K. (1999). The water-water cycle in chloroplasts: scavenging of active oxygens and dissipation of excess photons. Annu. Rev. Plant Physiol. Plant Mol. Biol. 50, 601-639. doi: 10.1146/annurev.arplant.50.1.601

Baker, N. R., and Bowyer, J. R. (1994). Photoinhibition of Photosynthesis: From Molecular Mechanisms to the Field. Oxford: BIOS Scientific Publishers.

Barbato, R., Race, H. L., Friso, G., and Barber, J. (1991). Chlorophyll levels in the pigment-binding proteins of photosystem II. A study based on the chlorophyll to cytochrome ratio in different photosystem II preparations. FEBS Lett. 286, 86-90. doi: 10.1016/0014-5793(91)80947-2

Barber, J., and Andersson, B. (1992). Too much of a good thing: light can be bad for photosynthesis. Trends Biochem. Sci. 17, 61-66. doi: 10.1016/09680004(92)90503-2

Barber, J., and De Las Rivas, J. (1993). A functional model for the role of cytochrome b559 in the protection against donor and acceptor side photoinhibition. Proc. Natl. Acad. Sci. U.S.A. 90, 10942-10946. doi: 10.1073/pnas.90.23.10942

Blankenship, R. E. (2002). Molecular Mechanisms of Photosynthesis. Oxford: Blackwell Science.

Breton, J., and Kato, S. (1987). Orientation of the pigments in photosystem II: low-temperature linear-dichroism study of a core particle and of its chlorophyll-protein subunits isolated from Synechococcus sp. Biochim. Biophys. Acta 892, 99-107. doi: 10.1016/0005-2728(87)90252-0

Crystall, B., Booth, P. J., Klug, D. R., Barber, J., and Porter, G. (1989). Resolution of a long lived fluorescence component from D1/D2/cytochrome b559 reaction centers. FEBS Lett. 249, 75-78. doi: 10.1016/0014-5793(89)80019-5

Dekker, J. P., and Van Grondelle, R. (2000). Primary charge separation in Photosystem II. Photosyn. Res. 63, 195-208. doi: 10.1023/A:1006468024245

De Las Rivas, J., Shipton, C. A., Ponticos, M., and Barber, J. (1993). Acceptor side mechanism of photoinduced proteolysis of the D1 protein in photosystem II reaction centers. Biochemistry 32, 6944-6950. doi: 10.1021/bi00078a019

Diner, B. A., and Rappaport, F. (2002). Structure, dynamics, and energetics of the primary photochemistry of photosystem II of oxygenic photosynthesis. Annu. Rev. Plant Biol. 53, 551-580. doi: 10.1146/annurev.arplant.53.100301.135238

Durrant, J. R., Giorgi, L. B., Barber, J., Klug, D. R., and Porter, G. (1990). Characterization of triplet states in isolated photosystem II reaction centers: oxygen quenching as a mechanism for photodamage. Biochim. Biophys. Acta 1017, 167-175. doi: 10.1016/0005-2728(90)90148-W

Ferreira, K. N., Iverson, T. M., Maghlaoui, K., Barber, J., and Iwata, S. (2004). Architecture of the photosynthetic oxygen-evolving center. Science 303, 1831-1838. doi: 10.1126/science. 1093087

Fleming, G. R., and van Grondelle, R. (1997). Femtosecond spectroscopy of photosynthetic light-harvesting systems. Curr. Opin. Struct. Biol. 7, 738-748. doi: 10.1016/S0959-440X(97)80086-3

Frank, H. A., and Brudvig, G. W. (2004). Redox functions of carotenoids in photosynthesis. Biochemistry 43, 8607-8615. doi: 10.1021/bi0492096

Gobets, B., and van Grondelle, R. (2001). Energy transfer and trapping in photosystem I. Biochim. Biophys. Acta 1507, 80-99. doi: 10.1016/S00052728(01)00203-1 
Gounaris, K., Chapman, D. J., Booth, P., Crystall, B., Giorgi, L. B., Klug, D. R., et al. (1990). Comparison of the D1/D2/cytochrome b559 reaction centre complex of photosystem two isolated by two different methods. FEBS Lett. 265, 88-92. doi: 10.1016/0014-5793(90)80890-U

Guergova-Kuras, M., Boudreaux, B., Joliot, A., Joliot, P., and Redding, K. (2001). Evidence for two active branches for electron transfer in photosystem I. Proc. Natl. Acad. Sci. U.S.A. 98, 4437-4442. doi: 10.1073/pnas.081078898

Haffa, A. L. M., Lin, S., Williams, J. C., Taguchi, A. K. W., Allen, J. P., and Woodbury, N. W. (2003). High yield of long-lived B-side charge separation at room temperature in mutant bacterial reaction centers. J. Phys. Chem. B 107, 12503-12510. doi: 10.1021/jp034703p

Hakala, M., Tuominen, I., Keranen, M., Tyystjarvi, T., and Tyystjarvi, E. (2005). Evidence for the role of the oxygen-evolving manganese complex in photoinhibition of Photosystem II. Biochim. Biophys. Acta 1706, 68-80. doi: 10.1016/j.bbabio.2004.09.001

Hoerber, J. K. H., Goebel, W., Ogrodnik, A., MichelBeyerle, M. E., and Cogdell, R. J. (1986). Timeresolved measurements of fluorescence from reaction centers of Rhodopseudomonas viridis and the effect of menaquinone reduction. FEBS Lett. 198, 268-272. doi: 10.1016/0014-5793(86)80418-5

Holzwarth, A. R., Muller, M. G., Reus, M., Nowaczyk, M., Sander, J., and Rogner, M. (2006). Kinetics and mechanism of electron transfer in intact photosystem II and in the isolated reaction center: pheophytin is the primary electron acceptor. Proc. Natl. Acad. Sci. U.S.A. 103, 6895-6900. doi: 10.1073/pnas.0505371103

Hou, H. J. M. (2008). "Identification of the degradation products involved in bacteriopheophytin photodamage of the photosynthetic reaction centers from $R b$. sphaeroides by liquid chromatographymass spectrometry," in Photosynthesis: Energy from the Sun, eds J. P. Allen, B. Osmond, J. H. Golbeck and E. Gantt (Dordrecht: Springer), 1473-1478.

Hou, H. J. M., Zhang, X., Liu, H., Steven, J., Young, E., Lien, T., et al. (2005). "Photodamage of one bacteriopheophytin molecule in the photosynthetic reaction center from $R b$ sphaeroides," in Photosynthesis: Fundamental Aspects to Global Perspertives, eds A. Van Der Est and D. Bruce (Lawrence: Allen Press), 501-503.

Hou, J. M., Dejonghe, D., Shan, J. X., Li, L. B., and Kuang T. Y. (2000). Orientation of pigments in the isolated photosystem II sub-core reaction center complex: a linear dichroism study, J. Integr. Plant Biol. 42, 1211-1214

Hou, J. M., Kuang, T. Y., Peng, D. C., Tang, C. Q., and Tang, P. (1996). The photodamage and protective role of pheophytin a in the photosystem II reaction center against light-induced damage. Prog. Nat. Sci. 6, 489-493.

Hou, J. M., Peng, D. C., Kuang, T. Y., Tang, C. Q., and Tang, P. (1995). Pheophytin A molecule association with primary photochemistry in the isolated photosystem II reaction center D1/D2/Cyt B559 complex. J. Integr. Plant Biol. 37, 405-408.

Hou, X., and Hou, H. J. M. (2013). Roles of manganese in photosystem II dynamics to irradiations and temperatures. Front. Biol. 8, 312-322. doi: 10.1007/s11515-012-1214-2
Hou, X., Raposo, A., and Hou, H. J. M. (2013). Response of chlorophyll d-containing cyanobacterium Acaryochloris marina to UV and visible irradiations. Photosynth. Res. 117, 497-507. doi: 10.1007/s11120-013-9946-7

Joliot, P., and Joliot, A. (1999). In vivo analysis of the electron transfer within photosystem I: are the two phylloquinones involved? Biochemistry 38 , 11130-11136.

Jordan, P., Fromme, P., Witt, H. T., Klukas, O., Saenger, W., and Krauss, N. (2001). Threedimensional structure of cyanobacterial photosystem I at 2.5 A resolution. Nature 411, 909-917. doi: $10.1038 / 35082000$

Klimov, V. V., Klevanik, A. V., Shuvalov, V. A., and Kransnovsky, A. A. (1977). Reduction of pheophytin in the primary light reaction of photosystem II. FEBS Lett. 82, 183-186. doi: 10.1016/00145793(77)80580-2

Kobayashi, M., Maeda, H., Watanabe, T., Nakane, H. and Satoh, K. (1990). Chlorophyll a and $\beta$-carotene content in the D1/D2/cytochrome b-559 reaction center complex from spinach. FEBS Lett. 260, 138-140. doi: 10.1016/0014-5793(90)80086-X

Kramer, D. M. (2010). The photonic smart grid of the chloroplast in action. Proc. Natl. Acad. Sci. U.S.A. 107, 2729-2730. doi: 10.1073/pnas.0914429107

Kuang, T. Y., Hou, J. M., Peng, D. C., Tang, C. Q., and Tang, P. (1995). Light-induced damage of pheophytin a molecule in the isolated photosystem II reaction center D1/D2/Cyt b559 complex. J. Integr. Plant Biol. 37, 401-404.

Li, Y., van der Est, A., Lucas, M. G., Ramesh, V. M., Gu, F., Petrenko, A., et al. (2006). Directing electron transfer within Photosystem I by breaking $\mathrm{H}$-bonds in the cofactor branches. Proc. Natl. Acad. Sci. U.S.A. 103, 2144-2149. doi: 10.1073/pnas.0506537103

Lin, S., Katilius, E., Haffa, A. L. M., Taguchi, A. K. W., and Woodbury, N. W. (2001). Blue light drives Bside electron transfer in bacterial photosynthetic reaction centers. Biochemistry 40, 13767-13773. doi: 10.1021/bi015612q

Loll, B., Kern, J., Saenger, W., Zouni, A., and Biesiadka, J. (2005). Towards complete cofactor arrangement in the 3.0 A resolution structure of photosystem II. Nature 438, 1040-1044. doi: 10.1038/ nature 04224

Maroti, P., Kirmaier, C., Wraight, C., Holten, D., and Pearlstein, R. M. (1985). Photochemistry and electron transfer in borohydride-treated photosynthetic reaction centers. Biochim. Biophys. Acta. 810, 132-139. doi: 10.1016/0005-2728 (85)90128-8

Martin, J. L., Breton, J., Hoff, A. J., Migus, A., and Antonetti, A. (1986). Femtosecond spectroscopy of electron transfer in the reaction center of the photosynthetic bacterium Rhodopseudomonas sphaeroides R-26: direct electron transfer from the dimeric bacteriochlorophyll primary donor to the bacteriopheophytin acceptor with a time constant of $2.8+-0.2$ psec. Proc. Natl. Acad. Sci. U.S.A. 83 957-961. doi: 10.1073/pnas.83.4.957

McTavish, H., Picorel, R., and Seibert, M. (1989). Stabilization of isolated photosystem II reaction center complex in the dark and in the light using polyethylene glycol and an oxygenscrubbing system. Plant Physiol. 89, 452-456. doi: $10.1104 /$ pp.89.2.452
Melis, A. (1999). Photosystem-II damage and repair cycle in chloroplasts: what modulates the rate of photodamage? Trends Plant Sci. 4, 130-135.

Michel-Beyerle, M. E., Plato, M., Deisenhofer, J., Michel, H., Bixon, M., and Jortner, J. (1988). Unidirectionality of charge separation in reaction centers of photosynthetic bacteria. Biochim. Biophys. Acta 932, 52-70. doi: 10.1016/00052728(88)90139-9

Murata, N., Takahashi, S., Nishiyama, Y., and Allakhverdiev Suleyman, I. (2007). Photoinhibition of photosystem II under environmental stress. Biochim. Biophys. Acta 1767, 414-421. doi: 10.1016/j.bbabio.2006.11.019

Nanba, O., and Satoh, K. (1989). Isolation of a photosystem II reaction center consisting of D1 and D-2 polypeptides and cytochrome b-559. Proc. Natl. Acad. Sci. U.S.A. 84, 109-112. doi: 10.1073/pnas.84.1.109

Niyogi, K. K. (1999). Photoprotection revisited: genetic and molecular approaches. Annu. Rev. Plant Physiol. Plant Mol. Biol. 50, 333-359

Ohnishi, N., Allakhverdiev, S. I., Takahashi, S., Higashi, S., Watanabe, M., Nishiyama, Y., et al. (2005). Two-step mechanism of photodamage to photosystem II: step 1 occurs at the oxygenevolving complex and step 2 occurs at the photochemical reaction center. Biochemistry 44, 8494-8499

Peng, D. C., Hou, J. M., Kuang, T. Y., Tang, C. Q., and Tang P. (1999). Photoinduced damage of the photosystem II primary electron donor P680: a high performance liquid chromatographic analysis of pigment content in D1/D2/cytochrome b559 complex under photoinhibitory conditions. J. Integr. Plant Biol. 41, 1307-1311

Powles, S. B. (1984). Photoinhibition of photosynthesis induced by visible light. Annu. Rev. Plant Physiol. 35, 15-44. doi: 10.1146/annurev.pp.35.060184.000311

Schatz, G. H., Brock, H., and Holzwarth, A. R. (1988). Kinetic and energetic model for the primary processes in photosystem II. Biophys. J. 54, 397-405. doi: 10.1016/S0006-3495(88)82973-4

Seibert, M., Picorel, R., Rubin, A. B., and Connolly, J. S. (1988). Spectral, photophysical, and stability properties of isolated photosystem II reaction center. Plant Physiol. 87, 303-306. doi: 10.1104/pp.87.2.303

Seibert, M., and Wasielewski, M. R. (2003). The isolated Photosystem II reaction center: first attempts to directly measure the kinetics of primary charge separation. Photosyn. Res. 76, 263-268. doi: 10.1023/A:1024986307839

Seibert, M., Yruela, I., and Picorel, R. (2004) Isolation of photosystem II reaction center complexes from plants. Methods Mol. Biol. 274, 53-62. doi: 10.1007/978-1-60761-925-3 3

Shinopoulos, K. E., and Brudvig, G. W. (2012). Cytochrome b559 and cyclic electron transfer within photosystem II. Biochim. Biophys. Acta 1817, 66-75. doi: 10.1016/j.bbabio.2011.08.002

Shinopoulos, K. E., Yu, J., Nixon P. J., and Brudvig, G. W. (2014). Using site-directed mutagenesis to probe the role of the $\mathrm{D} 2$ carotenoid in the secondary electron-transfer pathway of photosystem II. Photosynth Res. [Epub ahead of print].

Shipton, C. A., and Barber, J. (1991). Photoinduced degradation of the D1 polypeptide in isolated 
reaction centers of photosystem II: evidence for an autoproteolytic process triggered by the oxidizing side of the photosystem. Proc. Natl. Acad. Sci. U.S.A. 88, 6691-6695. doi: 10.1073/pnas.88.15.6691

Shipton, C. A., and Barber, J. (1994). In vivo and in vitro photoinhibition reactions generate similar degradation fragments of D1 and D2 photosystem-II reaction-centre proteins. Eur. J. Biochem. 220, 801-808. doi: 10.1111/j.14321033.1994.tb18682.x

Takahashi, Y., Hansson, O., Mathis, P., and Satoh, K. (1987). Primary radical pair in the photosystem II reaction center. Biochim. Biophys. Acta 893, 49-59. doi: 10.1016/0005-2728(87) 90147-2

Telfer, A. (2005). Too much light? How $\beta$-carotene protects the photosystem II reaction centre. Photochem. Photobiol. Sci. 4, 950-956. doi: 10.1039/b507888c

Telfer, A., and Barber, J. (1989). Evidence for the photoinduced oxidation of the primary electron donor P680 in the isolated photosystem II reaction center. FEBS Lett. 246, 223-228. doi: 10.1016/0014-5793 (89) $80287-\mathrm{X}$

Telfer, A., De las Rivas, J., and Barber, J. (1991). $\beta$-carotene within the isolated photosystem II reaction center: photooxidation and irreversible bleaching of this chromophore by oxidized P680. Biochim. Biophys. Acta 1060, 106-114. doi: 10.1016/S0005-2728 (05)80125-2

Telfer, A., Frolov, D., Barber, J., Robert, B., and Pascal, A. (2003). Oxidation of the two $\beta$ carotene molecules in the photosystem IIreaction center. Biochemistry 42, 1008-1015. doi: 10.1021/bi026206p

Telfer, A., He, W. Z., and Barber, J. (1990). Spectral resolution of more than one chlorophyll electron donor in the isolated photosystem II reaction center complex. Biochim. Biophys. Acta 1017, 143-151. doi: 10.1016/0005-2728(90)90145-T

Telfer, A., Marder, J. B., and Barber, J. (1987). Photosystem II reaction centers isolated from phosphorylated pea thylakoids carry phosphate on the D1 and D2 polypeptide subunits. Biochim. Biophys. Acta 893, 557-563. doi: 10.1016/00052728(87)90107-1

Thompson, L. K., and Brudvig, G. W. (1988) Cytochrome b-559 may function to protect photosystem II from photoinhibition. Biochemistry 27, 6653-6658. doi: 10.1021/bi00418a002

Tyystjarvi, E. (2008). Photoinhibition of Photosystem II and photodamage of the oxygen evolving manganese cluster. Coord. Chem. Rev. 252, 361-376. doi: 10.1016/j.ccr.2007.08.021

Umena, Y., Kawakami, K., Shen, J. R., and Kamiya, N. (2011). Crystal structure of oxygen-evolving photosystem II at a resolution of 1.9 A. Nature 473 55-61. doi: 10.1038/nature09913

Van Grondelle, R. (1985). Excitation energy transfer, trapping and annihilation in photosynthetic systems. Biochim. Biophys. Acta 811, 147-195. doi: 10.1016/0304-4173(85)90017-5

Van Grondelle, R., and Novoderezhkin, V. I. (2006). Energy transfer in photosynthesis: experimental insights and quantitative models. Phys. Chem. Chem. Phys. 8, 793-807. doi: 10.1039/b514032c

Wasielewski, M. R., Johnson, D. G., Seibert, M., and Govindjee. (1989). Determination of the primary charge separation rate in isolated photosystem II reaction centers with 500-fs time resolution. Proc. Natl. Acad. Sci. U.S.A. 86, 524-528. doi: 10.1073/pnas. 86.2.524

Wei, Z., Cady, C. W., Brudvig, G. W., and Hou, H. J. M. (2011). Photodamage of a Mn(III/IV)oxo mix valence compound and photosystem II complexes: evidence that high-valent manganese species is responsible for UV-induced photodamage of oxygen evolving complex in photosystem II. J. Photochem. Photobiol. B 104, 118-125. doi: 10.1016/j.jphotobiol.2011.01.017

Yu, Z., Kuang, T., Lu, R., Tang, C., and Tang, P. (1995). Light-induced damage of amino acid residues and degradation of polypeptides in D1/D2/cytochrome b559 complex. J. Integr. Plant Biol. 37, 267-273.

Received: 19 December 2013; accepted: 26 December 2013; published online: 13 January 2014.

Citation: Hou HJM (2014) Unidirectional photodamage of pheophytin in photosynthesis. Front. Plant Sci. 4:554. doi: 10.3389/fpls.2013.00554

This article was submitted to Plant Physiology, a section of the journal Frontiers in Plant Science.

Copyright (C) 2014 Hou. This is an open-access article distributed under the terms of the Creative Commons Attribution License (CC BY). The use, distribution or reproduction in other forums is permitted, provided the original author(s) or licensor are credited and that the original publication in this journal is cited, in accordance with accepted academic practice. No use, distribution or reproduction is permitted which does not comply with these terms. 